\title{
PENGEMBANGAN APLIKASI PEMBELAJARAN FISIKA BERBASIS ANDROID PADA MATERI GERAK LURUS KELAS X
}

\author{
Tri Hardila $^{1^{*}}$, Siti Anisatur Rofiqah ${ }^{1}$, Thoha Firdaus ${ }^{1}$ \\ ${ }^{1}$ Universitas Nurul Huda, OKU Timur \\ *Corresponding author: tri@stkipnurulhuda.ac.id
}

\author{
Article History: \\ Received: Oktober 02, 2021 \\ Revised: Oktober 23, 2021 \\ Accepted: Desember 03, 2021 \\ Published: Desember 31, 2021
}

Keywords: Android application, development, straight motion

\begin{abstract}
This study aims to describe the process of developing an Android-based physics learning application on straight motion material in grade 10. The development model used is DDD-E (Decide, Design, Develop, Evaluate). The subjects of this study were three material expert validators, three media expert validators, and 18 grade 10 students at the Mechanical School Engineering Vocational School for the 2020/2021 academic year. Data collection techniques used observation sheets, assessment sheets of media experts and material experts, and practicality trials of student responses which were used as data to determine the practicality of learning applications developed and analyzed with descriptive percentages. The results showed that the validity value of the media expert was 0.84 with high validity criteria and the validity value obtained from the material expert was 0.74 in the medium validity range. The results of the practicality test of student responses showed a value of $80.03 \%$ with appropriate criteria. Based on these data, it is concluded that this android-based physics learning application is valid and practical to be used as an independent learning media for students and as a teacher learning media.
\end{abstract}

\begin{abstract}
Abstrak: Penelitian ini bertujuan untuk mendeskripsikan proses pengembangan aplikasi pembelajaran fisika berbasis android pada materi gerak lurus kelas X. Model pengembangan yang digunakan adalah DDD-E (Decide, Design, Develop, Evaluate). Subjek penelitian ini adalah tiga validator ahli materi dan tiga validator ahli media serta peserta didik kelas X SMK Teknik Sekolah Mesin (TSM) tahun ajaran 2020/2021 yang berjumlah 18 orang. Teknik pengumpulan data menggunakan lembar observasi, lembar penilaian ahli media dan ahli materi serta uji coba kepraktisan respon peserta didik digunakan sebagai data untuk mengetahui kepraktisan aplikasi pembelajaran yang dikembangkan dan dianalisis dengan deskriptif persentase. Hasil penelitian diperoleh nilai validitas dari ahli media sebesar 0,84 dengan kriteria validitas tinggi dan nilai validitas yang diperoleh dari ahli materi sebesar 0,74 berada pada rentang validitas sedang. Sedangkan hasil uji coba kepraktisan respon peserta didik diperoleh 80,03\% dengan kriteria layak. Berdasarkan data tersebut disimpulkan bahwa aplikasi pembelajaran fisika berbasis android yang dikembangkan bersifat valid dan praktis untuk digunakan sebagai media pembelajaran mandiri peserta didik dan sebagai media pembelajaran guru.
\end{abstract}




\section{PENDAHULUAN}

Pendidikan sangat penting dalam kehidupan, tujuannya untuk meningkatkan kualitas sumber daya manusia untuk memajukan bangsa yang lebih baik (Syiam et al., 2020). Pendidikan suatu tolok ukur dalam kemajuan bangsa, karena pendidikan akan menghasilkan sumber daya manusia berkualitas (Damayanti et al., 2018). Maka pendidikan sangat penting dalam kemajuan bangsa untuk menghasilkan sumber daya manusia yang berkompeten dan berkualitas.

Pendidikan di era generasi millennial saat ini tidak lepas dengan teknologi dan internet. Seiring Perkembangan Teknologi, Informasi dan Komunikasi (TIK) di era generasi millennial merupakan hal pokok yang dapat mempengaruhi kehidupan seharihari. Teknologi Informasi Komunikasi (TIK) di Indonesia berkembang semakin pesat. Teknologi yang saat ini berkembang pesat adalah mobile learning yaitu smartphone berbasis android (Damayanti et al., 2018). Tahun 2018 lembaga riset digital marketing emarketer menyatakan bahwa jumlah aktif pengguna smartphone di Indonesia akan mencapai 100 juta orang. Dalam hal ini Indonesia akan berada pada urutan keempat negara pengguna smartphone (Astuti et al., 2017)

Seiring dengan bertambahnya penggunaan smartphone di berbagai kalangan masyarakat, pelajar maupun mahasiswa hanya menggunakan smartphone sebagai media sosial dan bermain game saja, hal ini dapat menggangu kegiatan belajar peserta didik serta mengurangi minat belajar. Mengatasi hal tersebut diperlukannya inovasi baru bahwa smartphone dapat digunakan sebagai media pembelajaran sehingga peserta didik lebih berminat dan tertarik untuk belajar. Media pembelajaran sebagai sarana untuk menyampaikan pesan atau informasi yang disampaikan oleh sumber pesan kepada penerima pesan (Ikhbal \& Musril, 2020). Bertambahnya pengguna smartphone di kalangan pelajar, maka potensi pengembangan media pembelajaran smartphone membuka peluang untuk mendukung aktivitas dalam dunia pendidikan (Amirullah \& Susilo, 2018).

Setelah dilakukan observasi di Sekolah Menengah Kejuruan (SMK) Negeri 1 Buay Pemuka Bangsa Raja media pembelajaran masih menggunakan papan tulis dan microsoft office powerpoint yang dihubungkan pada LCD proyektor. Sedangkan hasil observasi dengan memberikan lembar instrumen angket penilaian proses pembelajaran kepada peserta didik menunjukkan $56 \%$ dari 36 peserta didik setuju bahwa aspek pembelajaran fisika sangat sulit dipahami. Sedangkan pada aspek penilaian menunjukkan $50 \%$ peserta didik setuju bahwa kurangnya media pembelajaran sebagai penunjang pemahaman fisika sehingga dalam proses pempelajaran jenuh dan membosankan. Namun pendapat guru menyatakan bahwa peserta didiknya sangat antusias disaat berlangsungnya pembelajaran fisika, hanya beberapa saja peserta didik yang tidak antusias. Guru juga menyatakan peserta didiknya mampu mengikuti pembelajaran dengan baik, namun masih banyak peserta didik yang tidak memahami materi pembelajaran khususnya pelajaran fisika.

Pelajaran fisika merupakan pelajaran yang erat berhubungan dengan fenomena alam maupun pemanfaatannya dalam kehidupan sehari-hari (Anesia et al., 2018). Salah satu konsep fisika yang tanpa kita sadari 
sering dilakukan dalam kehidupan sehari-hari, yaitu konsep fisika gerak lurus. Namun berdasarkan observasi peserta didik kesulitan dalam mengkaitkan konsep fisika gerak lurus dalam kehidupan sehari-hari. Banyak faktor yang menyebabkan peserta didik kurang paham dalam konsep fisika gerak lurus salah satunya terlalu banyak rumus dalam pengaplikasiannya. Dalam pengaplikasian rumus atau perhitungan konsep fisika gerak lurus dalam kehidupan nyata sangat sulit untuk dijelaskan secara riil kepada peserta didik, sehingga perlunya inovasi baru dalam media pembelajaran yang dapat mempermudah peserta didik dalam pemahaman konsep fisika secara riil dan dapat mengubah mindset peserta didik agar lebih berminat dalam belajar.

Salah satu media yang dapat mengubah mindset serta dapat membantu pemahaman konsep fisika peserta didik adalah dengan memanfaatkan media pembelajaran sesuai dengan perkembangan teknologi dan media yang saat ini menjadi sahabat peserta didik seperti menggunakan smartphone berbasis android. Berdasarkan penelitian terdahulu dari, Damayanti et al., 2018 dengan judul "Kelayakan media pembelajaran fisika berupa buku saku berbasis android pada materi fluida statis" didalam penelitiannya dapat disimpulkan bahwa media pembelajaran berbasis android mendukung belajar lebih efektif dan praktis sebagai media pembelajaran mandiri peserta didik. Maka dari itu peneliti akan mengembangkan Aplikasi Pembelajaran Fisika Berbasis Android Pada Materi Gerak Lurus Kelas X. Sedangkan Perbedaan penelitian ini terletak pada model pengembangan, materi yang disajikan, objek penelitian dan subjek penelitian serta didalam aplikasi yang dikembangkan sudah terdapat animasi.
Model pengembangan aplikasi pembelajaran fisika berbasis android ini lebih mengembangkan media pembelajaran fisika yang interaktif dengan menggabungkan tiga komponen (visual, audio dan audio-visual) dalam aplikasi pembelajaran fisika berbasis android. Oleh karena itu diharapkan dengan adanya aplikasi pembelajaran fisika berbasis android mempermudah peserta didik memahami konsep fisika dan praktis dalam belajar.

\section{METODE PENELITIAN}

Penelitian ini menggunakan pengembangan Research and Development (R\&D) yang bertujuan menghasilkan suatu produk (Ratnasari et al., 2020). Model pengembangan yang digunakan adalah DDD-E (Decide, Design, Develop, Evaluate) dari Tegeh (2014:16).

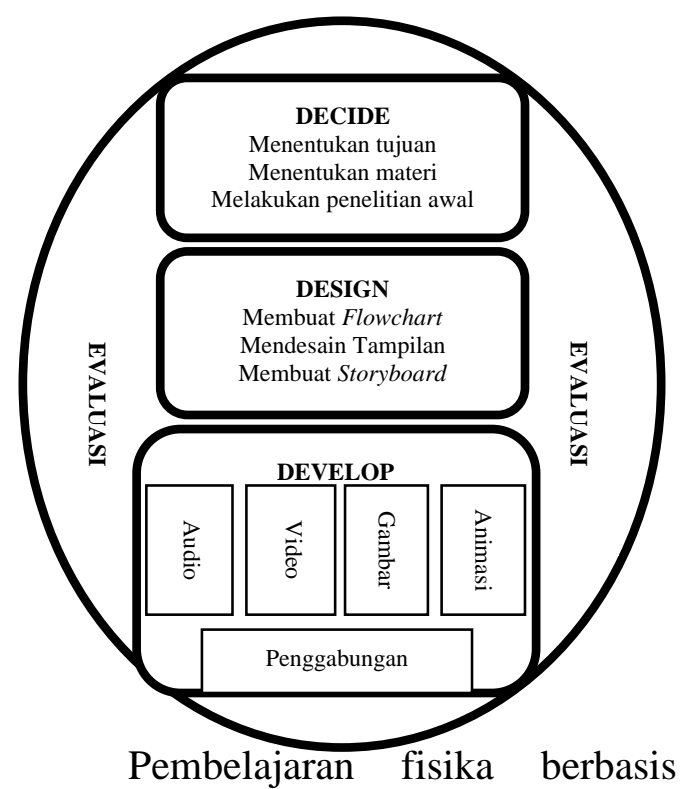
android dikembangkan dengan model DDDE, tahap pertama decide, yaitu: 1) menentukan tujuan pembelajaran; 2) menentukan tema atau ruang lingkup multimedia; dan 3) mengembangkan kemampuan prasyarat. Tahap kedua Design, yaitu: 1) Membuat outline konten; 2) Membuat flowchart; 3) Membuat tampilan; dan 4) Membuat storyboard. Tahap ketiga Develop, yaitu 
menggabungkan komponen multimedia. Tahap keempat Evaluate yaitu mengevaluasi setiap tahap dimulai dari Decide, Design, dan Develop. Dari setiap tahap akan dilakukan penilaian oleh ahli media dan ahli materi. Ahli media dan ahli materi untuk menjadi validator dalam menilai sejauh mana kelayakan atau kevalidan aplikasi pembelajaran fisika berbasis android. Setelah uji validitas, maka dilakukan uji coba respon peserta didik untuk mengetahui tingkat kepraktisan produk aplikasi.

Teknik

pengumpulan

menggunakan metode observasi untuk mengetahui kelengkapan media pembelajaran sekolah yang akan mendukung proses pembelajaran sesuai dengan produk yang akan dikembangkan dan metode angket digunakan untuk menganalisis kebutuhan siswa dalam proses pembelajaran. Lembar instrumen angket diberikan kepada siswa SMK Negeri 1 Buay Pemuka Bangsa Raja kelas X Teknik Sekolah Mesin (TSM) untuk mengetahui kebutuhan akan media pembelajaran fisika dan angket untuk uji ahli dan uji respon pengguna. Angket uji ahli dilakukan untuk validasi atau kelayakan produk pengembangan aplikasi pembelajaran fisika berbasis android oleh validator ahli media dan ahli materi. Angket uji respon pengguna digunakan untuk mengumpulkan data kepraktisan produk.

Teknik analisis data validasi ahli menggunakan rumus Aiken $\mathrm{V}$ (Retnawati, Heri. 2016) . Seperti pada persamaan 1 .

$$
V=\frac{\sum s}{n(c-1)}
$$

Keterangan:

$\mathrm{V}=$ Indeks kesepakatan rater
$\mathrm{S}=$ Skor yang ditetapkan setiap rater dikurang skor terendah dalam kategori yang dipakai $\left(\mathrm{s}=\mathrm{r}-\mathrm{l}_{0}\right)$ dengan $\mathrm{r}=$ skor kategori rater dan $\mathrm{I}_{0}$ $=$ skor terendah dalam kategori penyekoran)

$\mathrm{n}$ = Banyaknya rater

c = Banyaknya kategori dipilih rater Indeks $\mathrm{V}$ ini nilainya berkisaran

antara $\quad 0-1 . \quad$ Kriteria validasi pengembangan aplikasi pembelajaran fisika dapat dilihat pada tabel 1 .

Tabel 1. Kategori validasi pengembangan aplikasi pembelajaran fisika berbasis android dengan rumus Aiken $\mathrm{V}$

\begin{tabular}{cc}
\hline Rentang & Kevalidan \\
\hline$<0,4$ & Validitas Rendah \\
$0,4-0,8$ & Validitas Sedang \\
$>0,8$ & Validitas Tinggi \\
\hline
\end{tabular}

Pengelolaan data hasil angket respon peserta didik dianalisis menggunakan rumus (Suharmi. 2006). Seperti pada persamaan 2 .

$$
P=\frac{\sum x}{\sum x_{i}} \times 100 \%
$$

Keterangan:

$\mathrm{P}=$ Persentase Kepraktisan

$\sum \boldsymbol{x}=$ Jumlah jawaban responden dalam seluruh yang diberikan oleh subjek uji

$\sum \boldsymbol{x}_{\boldsymbol{i}}=$ Jumlah seluruh peserta didik

Tabel 2. Kategori respon peserta didik

\begin{tabular}{cl}
\hline Persentase \% & Keterangan \\
\hline $89 \geq \mathrm{P} \leq 100$ & Sangat Layak \\
$74 \geq \mathrm{P} \leq 89$ & Layak \\
$64 \geq \mathrm{P} \leq 74$ & Cukup Layak \\
$0 \geq \mathrm{P} \leq 64$ & Kurang Layak \\
$\mathrm{P} \leq 0$ & Tidak Layak \\
\hline
\end{tabular}

\section{HASIL DAN PEMBAHASAN}

Proses pengembangan dilakukan dengan menggabungkan setiap komponen produk menjadi sebuah aplikasi pembelajaran fisika berbasis android dengan memanfaatkan perkembangan software microsoft 
powerpoint yang akan mempermudah pembuatan media pembelajaran interaktif (Nurhidayati et al., 2019). Setelah dilakukan pengembangan, dilakukan validasi para hali media dan ahli materi untuk mengetahui kevalidan aplikasi pembelajaran fisika berbasis android yang dikembangkan. Validasi aplikasi ini dilakukan oleh 3 ahli media dan 3 ahli materi. Hasil validasi ahli media dan ahli materi pada aplikasi disajikan pada tabel 3 dan tabel 4 .

Tabel 3. Hasil validasi ahli media

\begin{tabular}{ccc}
\hline \multirow{2}{*}{ No } & Aspek yang Dinilai & $\begin{array}{c}\text { V (Indeks } \\
\text { validasi) }\end{array}$ \\
\hline 1 & Kesederhanaan aplikasi & 0,89 \\
2 & Keterpaduan multimedia & 0,86 \\
3 & Penekanan multimedia & 0,78 \\
& Rata-rata indeks validasi & 0,84 \\
\hline
\end{tabular}

Berdasarkan hasil analisis pada tabel 3 diperoleh rata-rata penilaian 0,84 . Indeks $\mathrm{V}$ ini nilainya berkisaran antara 0-1. Kriteria yang digunakan dapat dilihat pada tabel 1. Sehingga untuk aspek media berada pada rentang kevalidan $>0,8$ yang menunjukkan kriteria tingkat validitas tinggi.

Tabel 4. Hasil validasi ahli materi

\begin{tabular}{clc}
\hline No & Aspek yang Dinilai & $\begin{array}{c}\text { V (Indeks } \\
\text { validasi) }\end{array}$ \\
\hline 1 & Kesesuaian materi & 0,78 \\
2 & Kesesuaian soal & 0,76 \\
3 & Kebahasaan & 0,67 \\
\multicolumn{2}{c}{ Rata-rata indeks validasi } & 0,74 \\
\hline
\end{tabular}

Hasil analisis validasi ahli materi diperoleh rata-rata penilaian 0,74 dengan indeks $\mathrm{V}$ pada rentang kevalidan 0,4-0,8 , bahwa aspek materi dengan validitas sedang. Namun hasil analisis serta saran dan kritikan dari validator masih perlu dilakukan revisi sesuai dengan arahan validator.

Tahap pengembangan dilakukan validasi terdahulu sebelum dilakukan uji coba. Validasi dilakukan oleh para ahli aspek media dan ahli aspek materi untuk mengetahui tingkat kevalidan dari aplikasi pembelajaran fisika berbasis android. Setelah dilakukan validasi, maka dilakukan revisi sesuai dengan saran validator. Selanjutnya untuk mengetahui tingkat kepraktisan aplikasi pembelajaran fisika berbasis android yang dikembangkan, maka dilakukan uji kepraktisan respon pengguna oleh peserta didik terhadap aplikasi pembelajaran. Angket digunakan sebagai alat pengumpulan data selama uji coba respon peserta didik terhadap produk. Terdapat tiga aspek indikator yang dinilai peserta didik, yaitu kualitas isi, kualitas intruksional dan kualitas teknis. Berdasarkan hasil kepraktisan respon peserta didik diperoleh rata-rata persentase $80,03 \%$ dengan kriteria layak. Berdasarkan hasil analisis data ahli media, ahli materi dan uji kepraktisan disimpulkan bahwa aplikasi pembelajaran fisika berbasis android yang dikembangkan bersifat valid dan praktis untuk digunakan sebagai media pembelajaran mandiri peserta didik dan sebagai media pembelajaran guru serta sekaligus dapat memberikan kesenangan dalam belajar fisika (Marhadini et al., 2017)

Hasil penelitian ini didukung beberapa penelitian relavan bahwa media pembelajaran fisika berbasis android layak digunakan sebagai media pembelajaran mandiri peserta didik. Seperti hasil penelitian dari, Damayanti et al., 2018 dengan judul "Kelayakan media pembelajaran fisika berupa buku saku berbasis android pada materi fluida statis", Astuti et al., 2017 dengan judul "Pengembangan media pembelajaran fisika mobile learning berbasis android", dan G. Amirullah \& Susilo (2018) dengan jurnal "Pengembangan media pembelajaran interaktif pada konsep monera berbasis smartphone android", didalam penelitiannya dapat disimpulkan bahwa media pembelajaran berbasis android mendukung belajar lebih efektif dan praktis sebagai media pembelajaran 
mandiri peserta didik. Sedangkan Perbedaan penelitian ini terletak pada model pengembangan, materi yang disajikan, objek penelitian dan subjek penelitian serta didalam aplikasi yang dikembangkan sudah terdapat animasi.

Hasil tampilan aplikasi pembelajaran fisika berbasis android yang telah dikembangkan dapat dilihat pada gambar 1, 2, 3 dan 4 .

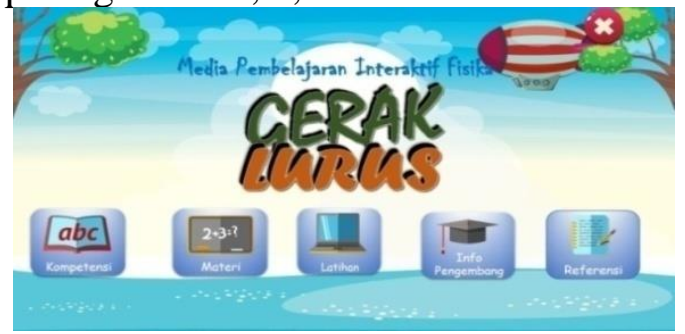

Gambar 1. Tampilan menu utama aplikasi pembelajaran fisika berbasis android

Menu utama pembelajaran fisika menampilkan fitur ataupun tombol pilihan seperti kompetensi, materi, latihan, info pengembang dan referensi. Tampilan menu utama dibuat sederhana agar menarik dan mempermudah peserta didik atau pengguna dalam menggunakan aplikasi tersebut.

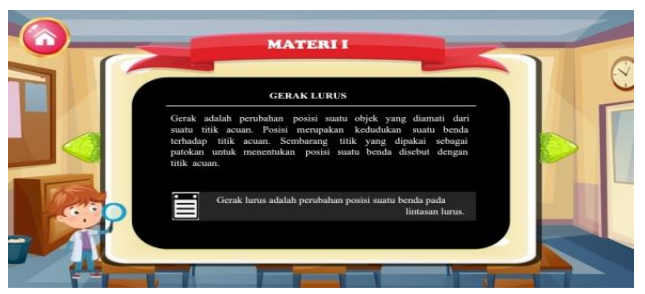

Gambar 2. Tampilan halaman materi

Halaman materi adalah halaman yang didalamnnya terdapat materimateri yang akan dijelaskan yang dilengkapi dengan gambar, animasi dan contoh soal terkait dengan materi.

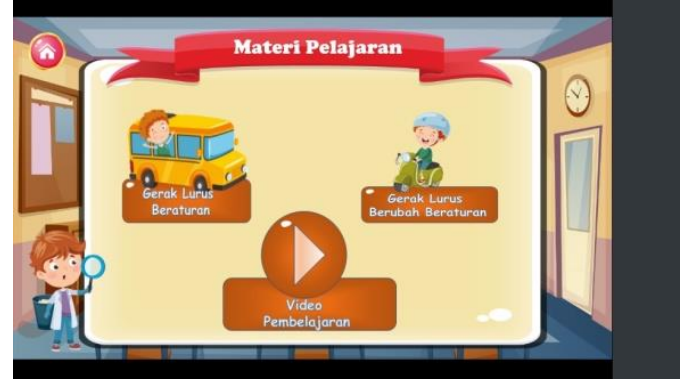

Gambar 3. Tampilan halaman video pembelajaran

Video pembelajaran diharapkan dapat memotivasi peserta didik untuk lebih semangat belajar dan dapat mempermudah memahami materi yang disajikan.

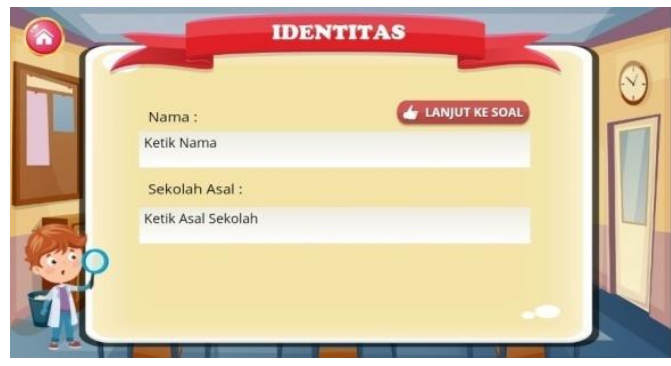

Gambar 4. Tampilan halaman evaluasi/latihan

Latihan/evaluasi adalah halaman yang didalamnnya terdapat soal-soal pilihan ganda yang akan dikerjakan peserta didik untuk mengetahui kemampuan peserta didik.

\section{PENUTUP}

\section{KESIMPULAN}

Berdasarkan hasil penelitian pengembangan aplikasi pembelajaran fisika berbasis android pada materi gerak lurus kelas $\mathrm{X}$, diperoleh dari ahli media sebesar 0,84 berada rentang kategori validitas tinggi dan nilai aspek materi diperoleh dari ahli materi sebesar 0,74 berada pada rentang validitas sedang. Sedangkan hasil uji coba kepraktisan respon peserta didik diperoleh 80,03\% dengan kriteria layak. Berdasarkan hasil tersebut disimpulkan 
bahwa aplikasi pembelajaran fisika berbasis android bersifat valid dan praktis untuk digunakan sebagai media pembelajaran mandiri peserta didik dan sebagai media pembelajaran guru.

\section{SARAN}

Bagi peneliti lain diharapkan adanya penelitian lanjut sehingga dapat menambahkan tampilan aplikasi yang menarik dan sampai pada tahap efektifitas.

\section{UCAPAN TERIMAKASIH}

Terimakasih para validator yang telah bersedia untuk memberikan penilaian dan saran serta masukkan untuk pengembangan aplikasi pembelajaran fisika berbasis android.

\section{REFERENSI}

Anesia, R, Nugroho, B. \& Gunawan, I. (2018). Pengembangan Media Komik berbasis Android pada Pokok Bahasan Gerak Lurus |Anesia| Indonesian Journal of Science and Mathematics Education.

http://ejournal.radenintan.ac.id/i ndex.php/IJSME/article/view/27 74

Amirullah, G., \& Susilo, S. (2018). Pengembangan Media Pembelajaran Interaktif Pada Konsep Monera Berbasis Smartphone Android. WACANA AKADEMIKA: Majalah Ilmiah Kependidikan, 2(1), 38-47. https://doi.org/10.30738/wa.v2i1 .2555

Astuti, I. A. D., Sumarni, R. A., \& Saraswati, D. L. (2017). Pengembangan Media Pembelajaran Fisika Mobile Learning berbasis Android. Jurnal Penelitian \& Pengembangan Pendidikan Fisika, 3(1), 57-62. https://doi.org/10.21009/1.03108
Damayanti, A. E., Syafei, I., Komikesari, H., \& Rahayu, R. (2018). Kelayakan Media Pembelajaran Fisika Berupa Buku Saku Berbasis Android pada Materi Fluida Statis. Indonesian Journal of Science and Mathematics Education, l(1), 63-70. https://doi.org/10.24042/ijsme.v $1 \mathrm{i} 1.2476$

Ikhbal, M., \& Musril, H. A. (2020). Perancangan Media Pembelajaran Fisika Berbasis Android. Information Management For Educators And Professionals: Journal of Information Management, 5(1), 15-24.

https://doi.org/10.51211/imbi.v5 i1.1411

Marhadini, S. A. K., Akhlis, I., \& Sumpono, I. (2017). Pengembangan Media Pembelajaran Berbasis Android pada Materi Gerak Parabola Untuk Siswa SMA. UPEJ Unnes Physics Education Journal, 6(3), 38-43. https://doi.org/10.15294/upej.v6i 3.19315

Nurhidayati, N., Asrori, I., Ahsanuddin, M., \& Dariyadi, M. W. (2019). Pembuatan Media Pembelajaran Berbasis Powerpoint Dan Pemanfaatan Aplikasi Android Untuk Guru Bahasa Arab. Jurnal KARINOV, 2(3), 181184.

https://doi.org/10.17977/um045v 2i3p181-184

Ratnasari, D., Oktaviyanti, D., Sukmawati, S. S., \& Setiyawati, E. (2020). Pengembangan Mobile Learning Berbasis Program APPYPIE untuk Pembelajaran Fisika. Jurnal 
Penelitian Pendidikan Fisika,

5(2),

158-163.

https://doi.org/10.36709/jipfi.v5i

2.13149

Retnawati, Heri. 2016. Analisis

Kuantitatif Intrumen Penelitian

(Panduan penelitian mahasiswa dan psikometrian). Yogyakarta:

Parama Publishing

Suharmi, Arikunto. 2006. Prosedur Penelitian Suatu Pendekatan Praktik. Jakarta: Rineka Cipta

Syiam Sholekhah, E, Anisatur Rofiqah, S. \& Effendi, E. (2021). Model Pembelajaran Treffinger: Pengaruh Penerapan terhadap Hasil Belajar Fisika Materi Kalor. U-Teach: Journal Education of Young Physics Teacher, 1(2), 67-75. https://doi.org/10.30599/uteach. v1i2.32

Tegeh, I $\mathrm{M}$ ade. Jampel, I Nyoman, Ketut. 2014. Model Penelitian Pengembangan. Yogyakarta: Graha Ilmu 